\title{
Regulatory Effect of Cannabidiol (CBD) on Decreased $\beta$-Catenin Expression in Alopecia Models by Testosterone and PMA Treatment in Dermal Papilla Cells
}

\author{
Yoon-Jong Park ${ }^{1}$, Jae-Min Ryu ${ }^{1}$, Han-Heom $\mathrm{Na}^{1,2}$, Hyun-Suk Jung ${ }^{2,3}$, Bokhye Kim ${ }^{2}$, Jin-Sung Park ${ }^{4}$, \\ Byung-Soo Ahn ${ }^{4,5}$, Keun-Cheol Kim ${ }^{1,2}$ *

\begin{abstract}
${ }^{2}$ Kangwon Center for System Imaging, Kangwon National University, Chuncheon, Republic of Korea
${ }^{3}$ Department of Biochemistry, College of Natural Sciences, Kangwon National University, Chuncheon, Republic of Korea

${ }^{4}$ Korean Pharmacopuncture Institute, Seoul, Republic of Korea

${ }^{5}$ Department of Pharmacy, College of Pharmacy, Ajou University, Suwon, Republic of Korea
\end{abstract} \\ ${ }^{1}$ Department of Biological Sciences, College of Natural Sciences, Kangwon National University, Chuncheon, Republic of Korea
}

Received May 30, 2021

Reviewed May 31, 2021

Accepted June 4, 2021

* Corresponding Author Keun-Cheol Kim

Department of Biological Sciences,

College of Natural Sciences, Kangwon National University, \#1, KangwonDaehak Rd., Chuncheon 24341, Republic of Korea

Tel: +82-33-250-8532

E-mail: kckim@kangwon.ac.kr
Objectives: The hair follicle is composed of more than 20 kinds of cells, and mesoderm derived dermal papilla cells and keratinocytes cooperatively contribute hair growth via Wnt/ $\beta$-catenin signaling pathway. We are to investigate $\beta$-catenin expression and regulatory mechanism by CBD in alopecia hair tissues and dermal papilla cells.

Methods: We performed structural and anatomical analyses on alopecia patients derived hair tissues using microscopes. Pharmacological effect of CBD was evaluated by $\beta$-catenin expression using RT-PCR and immunostaining experiment.

Results: Morphological deformation and loss of cell numbers in hair shaft were observed in alopecia hair tissues. IHC experiment showed that loss of $\beta$-catenin expression was shown in inner shaft of the alopecia hair tissues, indicating that $\beta$-catenin expression is a key regulatory function during alopecia progression. Consistently, $\beta$-catenin expression was decreased in testosterone or PMA treated dermal papilla cells, suggesting that those treatments are referred as a model on molecular mechanism of alopecia using dermal papilla cells. RT-PCR and immunostaining experiments showed that $\beta$-catenin expression was decreased in RNA level, as well as decreased $\beta$-catenin protein might be resulted from ubiquitination. However, CBD treatment has no changes in gene expression including $\beta$-catenin, but the decreased $\beta$-catenin expression by testosterone or PMA was restored by CBD pretreatment, suggesting that potential regulatory effect on alopecia induction of testosterone and PMA.

Conclusion: CBD might have a modulating function on alopecia caused by hormonal or excess of signaling pathway, and be a promising application for on alopecia treatment.

Keywords: alopecia, dermal papilla, wnt/ $\beta$-catenin, testosterone, phorbol 12-myristate 13-acetate (PMA), cannabidiol (CBD)

\section{INTRODUCTION}

Mammalian hair growth is begun from hair follicles in the dermis, which are composed of more than 20 kinds of cells [1]. It is known that hair growth is regulated through proliferation and differentiation of keratinocytes by the Wnt $/ \beta$-catenin pathway from dermal papilla cells that is in the stemness niche of the hair follicle [2]. Cyclic hair growth is progressed by anagen, catagen and telogen by which are multicellular signaling in hair follicle [3]. At the anagen stage, $\beta$-catenin is translocated into 
the nucleus and stimulates the expression and releases of FGF growth factors such as FGF7 and FGF10 [4, 5]. FGF growth factors activate the FGF receptor 2 (FGFr2) of keratinocytes in order to progress hair growth [6-8]. Ubiquitination of $\beta$-catenin has been suggested as pivotal regulatory mechanism to hair growth cycle $[9,10]$. Alopecia is a degenerated disease of hair growth that could be affected by environmental or genetic factors [11]. Especially, cyclic hair growth is defected in the steps from telogen phase to anagen reentry in alopecia [12-14].

Testosterone is the primary steroidal hormone of males in human population, and promote secondary sexual characteristics such as muscle, or bone formation [15]. Hormonal action of testosterone is known to regulate the $\mathrm{Wnt} / \beta$-catenin pathway in dermal papilla cells [16]. Testosterone is converted to dihydrotestosterone (DHT) by $5 \alpha$-reductase $(5 \alpha-\mathrm{R})$ in cytoplasmic region of dermal papilla cells $[17,18]$. DHT shows higher receptor binding capacity than testosterone, and increases the expression of GSK-3 $\beta$, DKK-1, IL- 6 , and TGF-b1, IL-6 and TGF- $\beta 1$ [2]. DHT inhibits the entering into catagen stage of keratinocytes during cyclic hair growth, indicating that defect of testosterone may be the cause of alopecia $[19,20]$. On the other hand, phorbol 12-myristate 13-acetate (PMA) also induces early catagen by regulating the PKC isoforms $(\alpha, \varepsilon, \lambda, 1, \gamma)$ of dermal papilla [21].

Cannabidiol (CBD) is a phytocannabinoid extracted from Hemp (Cannaivis sativa), and is used as a medicine for epilepsy treatment $[22,23]$. Whereas $\Delta^{9}$-tetrahydrocannabinol $\left(\Delta^{9}\right.$-THC), the main psychotropic phytocannabinoid of Hemp species (Cannabis marijuana), is a partial agonist $\mathrm{CB}_{1}$ and $\mathrm{CB}_{2}$ receptor, $\mathrm{CBD}$ act as an antagonist of $\mathrm{CB}_{1} / \mathrm{CB}_{2}$ agonists [24]. In contrast to $\Delta^{9}$-THC, The possibility as therapeutic agents has been increased due to CBD lacks detectable psychoactivity [25]. CBD inhibits apoptosis by inducing Erk and AKT/mTOR pathways in SH-SY5Y cell lines, suggesting that CBD has a potential therapeutic effect for parkinson's disease [26]. Moreover, CBD treatment regulates proliferation via activation of $\mathrm{CB}_{1}$ receptor of keratinocytes in hair follicles [27].

In this study, we are to investigate a possible regulatory mechanism of CBD in testosterone or PMA induced alopecia model. We performed microscopic analyses using alopecia patients derived hair. In addition, pharmacological effect of CBD was evaluated by $\beta$-catenin expression using RT-PCR and immunostaining experiment.

\section{MATERIALS AND METHODS}

\section{Cell cultures, and reagents}

Human dermal papilla cells were kindly obtained from Dr. YK Seo, Dongguk university, Ilsan, Korea. Cells were cultured in DMEM medium containing $10 \%$ fetal bovine serum and maintained in a humidified incubator at $37^{\circ} \mathrm{C} / 5 \% \mathrm{CO}_{2}$. Testosterone and phorbol 12-myristate 13-acetate (PMA) were obtained from Sigma Aldrich, and cannabidiol (CBD) from Cayman Inc, USA. The drugs were dissolved in appropriate solvents according to the manufacturer's protocol. Cell counting was performed using trypan blue staining (Gibco, USA).

\section{Hair tissues analyses}

Normal and alopecia hair tissues were collected from volunteers, and used for H\&E staining and Immunohistochemistry. This study was performed after approval from the Institutional Review Board (IRB) of Kangwon National University (KWNU IRB-2020-06-010-001). Hair tissues were fixed with 4\% formaldehyde, and then paraffin blocks were prepared. The sliced tissue sections were prepared using a microtome. The tissues were stained with hematoxylin and eosin, and observed with optical microscope (CX-200TM, COXEM, Korea). For immunohistochemistry experiment, the tissues were undergone for antigen retrieval using sodium citrate buffer $(10 \mathrm{mM}$ sodium citrate, $0.05 \%$ tween $20, \mathrm{pH} 6.0$ ) to heat for 15 minutes. The tissues were incubated with $\beta$-catenin antibody (1:100; Bdscience, USA) and then followed by secondary peroxidase antibody. The tissues were exposed for 1 minute using DAB substrate kit (Vector, USA). The hairs were also subjected to scanning electron microscopic (SEM) analysis (CX-200TM, COXEM, Korea).

\section{RNA extraction and RT-PCR}

Human dermal papilla cells $\left(4 \times 10^{5}\right)$ were seeded in $100 \mathrm{~mm}$ culture dish, and was treated with the drugs. Total RNA was isolated using the TRIZOL kit (Duchefa, Netherlands). Complementary DNA (cDNA) was synthesized with Oligo-dT primer and Reverse transcriptase (RTase). cDNA was mixed with specific primer sets in $0.2 \mathrm{mM}$ dNTP, KnTaq polymerase, buffer containing $1.5 \mathrm{mM} \mathrm{MgCl}_{2}$ (Enzynomics, Korea). PCR reactions were carried out in a Perkin Elmer Thermal Cycler 9600 (Applied Biosystems, MA, USA). PCR products were resolved 
in $2 \%$ agarose gels.

\section{Immunostaining}

Dermal papilla cells were cultured on the coverslips and fixed with $100 \%$ methanol solution. After washing with PBS, the cells were permeabilized with $0.2 \%$ Triton X-100 solution for $10 \mathrm{~min}$. Blocking was performed using 3\% bovine serum albumin in PBS for $1 \mathrm{hr}$, and followed by incubation with $\beta$-catenin antibodies (1:300) at room temperature for $2 \mathrm{hr}$. Cells were then washed with PBS, and followed by incubation with secondary antibodies Alexa 488 goat anti-mouse IgG (1:500; Abcam, USA). Cells were stained with DAPI for counter staining. The coverslips were mounted on the slide glass with antifade reagent. Fluorescent images were examined with confocal microscopes (Ts2, Nikon, Japan) of Kangwon center for system imaging (KCSI).

\section{RESULTS AND DISCUSSION}

Growth and degeneration of hair is cyclically regulated via various molecular signaling pathway [28]. Alopecia hair loss could be progressed by various reasons such as aging or hormonal changes on cells in hair follicle tissues $[11,12]$. The Wnt/ $\beta$-catenin pathway of dermal papilla cells regulates growth of hair, as well as is known as a key signaling pathway for proliferation and differentiation of keratinocytes in hair follicle [9, $10]$.
In this study, we investigated structural analyses and $\beta$-catenin expression between normal and alopecia hair tissues, as well as how CBD regulates $\beta$-catenin expression which is induced by testosterone or PMA in human dermal papilla cells. One of the characteristics of alopecia is changes in length or diameter of hair. We compared morphological characteristics between normal and alopecia hair tissues using SEM. The bulb of the alopecia hair tissues was severely deformed, and the surface of the hair shaft was irregular, suggesting that alopecia hair was severely damaged compared to normal hair (Fig. 1A). We also compared cell composition between normal and alopecia hair tissues using $\mathrm{H} \& \mathrm{E}$ staining (Fig. 1B). Cell density was less compact in alopecia hair tissues than normal hair tissues. Cells without nuclei were even observed in alopecia hair tissues, implying that the hair tissues and cell density were impaired in alopecia. Therefore, this phenomenon could be explained as induction of cell death mechanism such as apoptotic pathway by a decrease in differentiation and proliferation of keratinocytes during alopecia progression [29]. Immunohistochemistry experiment was performed to determine whether there was a difference in $\beta$-catenin expression in the shaft of normal and alopecia hair tissues. Interestingly, $\beta$-catenin was highly expressed in inner hair shaft region of normal hair tissues, but no expression in alopecia hair shaft (Fig. 1C). $\beta$-catenin expression is closely associated with proliferation and differentiation of dermal papilla cells but there have been few studies on functional roles of $\beta$-catenin expression of keratinocytes in the hair shaft region [30]. Our current data suggest that $\beta$-catenin is

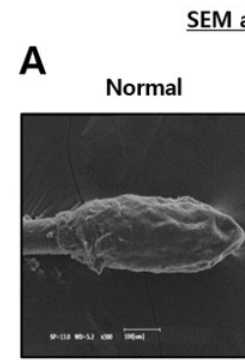

SEM analysis
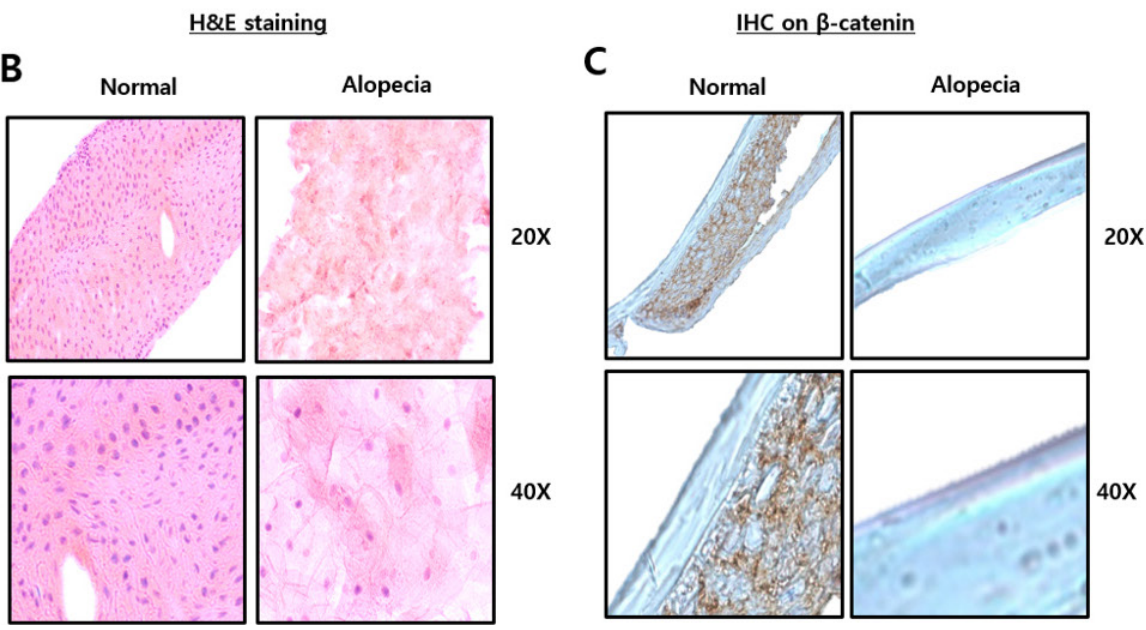

Figure 1. Alopecia hair is deformed and does not express $\beta$-catenin. (A) Normal and alopecia hairs were sliced into bulb and shaft, and then observed through an scanning electron microscope (SEM). (B) Normal and alopecia hairs was used for H\&E staining. (C) The expression of $\beta$-catenin was measured through immunohistochemistry. 
highly expressed to maintain proliferation of keratinocyte, but the loss of $\beta$-catenin expression might be a reason for alopecia progression.

Testosterone has been known as causative androgenic hormones of male alopecia in human population [15, 17]. High levels testosterone is convert into DHT, which can reduce growth and size of cells in hair follicles [18]. Testosterone was treated on culturing dermal papilla cells to examine molecular changes of gene expression. There was no significant growth inhibitory effect by testosterone treated dermal papilla cells (Fig. 2A). However, RT-PCR analysis showed that expression of wnt5a and $\beta$-catenin were decreased by testosterone treatment. We also performed immunostaining experiment on $\beta$-catenin expression in testosterone treated dermal papilla cells. Expression of $\beta$-catenin was decreased in this experiment, suggesting that $\beta$-catenin is regulated by testosterone. On the other hand, PMA, a PKC activator, has been also known as regulating $\beta$-catenin expression, and PMA was treated in dermal papilla cells. Using RT-PCR and immunostaining experiment, we obtained similar data that $\beta$-catenin expression was regulated by PMA treatment (Fig. 2B). These data suggest that $\beta$-catenin has an essential function for the growth and maintenance of dermal papilla cells in hair follicles. Moreover, appropriate $\beta$-catenin expression could be required for the differentiation into keratinocytes of hair tissues [3]. In the absence of $\beta$-catenin, dermal papilla cells are fail to adopt the fate of hair keratinocytes and instead, differentiate into epidermal keratinocytes [31]. We also performed immunostaining experiment using proteasome inhibitor MG132 to examine on the decreased $\beta$-catenin level. Decreased $\beta$-catenin expression by testosterone was increased in MG132 treatment (Fig. 3). Therefore, $\beta$-catenin level is tightly regulated by ubiquitination pathway in dermal papilla cells.

There are some reports that CBD in dissolved in hemp oil can promote the growth of the hair, but this pharmacological
A

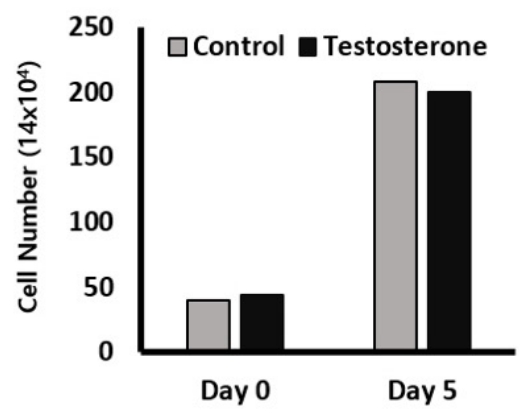

B

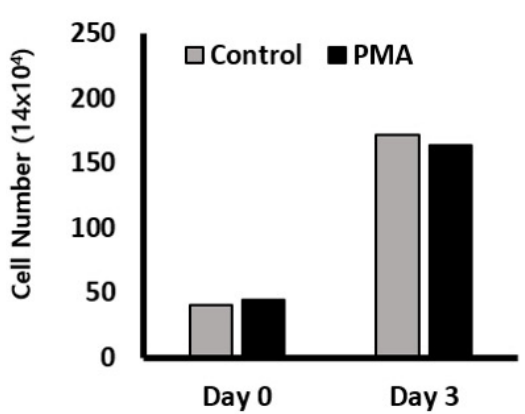

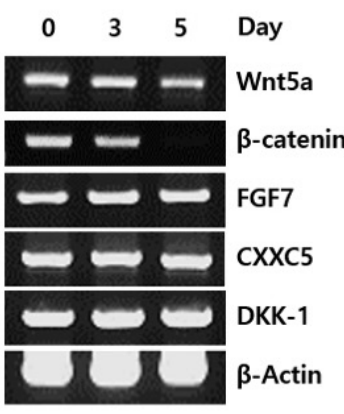

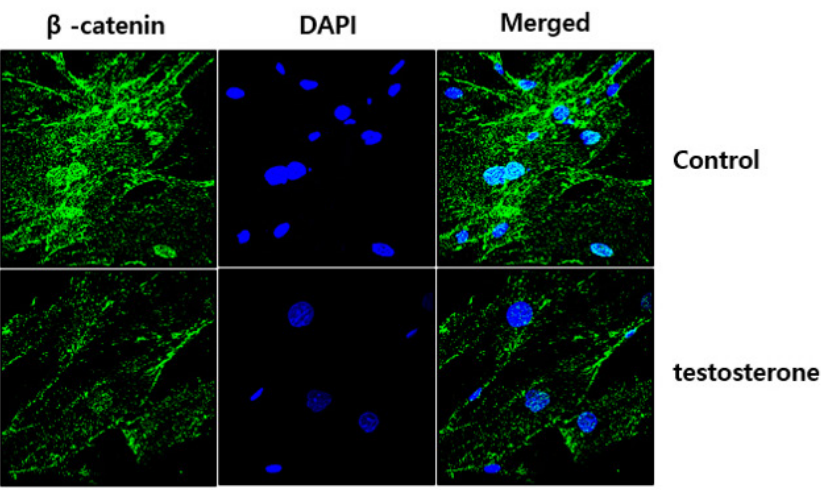

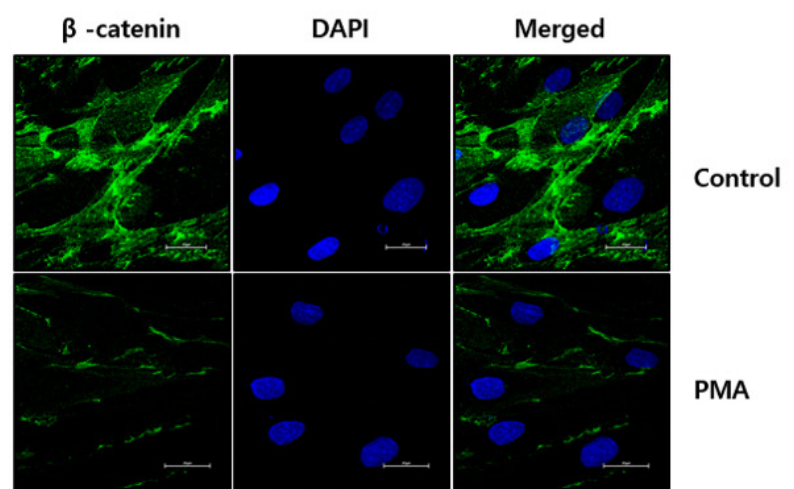

Figure 2. $\beta$-catenin is decreased by testosterone and PMA treatment in dermal papilla cells. (A) Dermal papilla cells were treated with testosterone for 5 days, and then analyzed on cell growth and gene expression. It was confirmed that $\beta$-catenin expression was decreased in testosterone treated dermal papilla cells using RT-PCR and immunostaining experiment. (B) PMA also treated for 3 days in dermal papilla cells, and followed by the same experiments as shown in testosterone treated dermal papilla cells. 

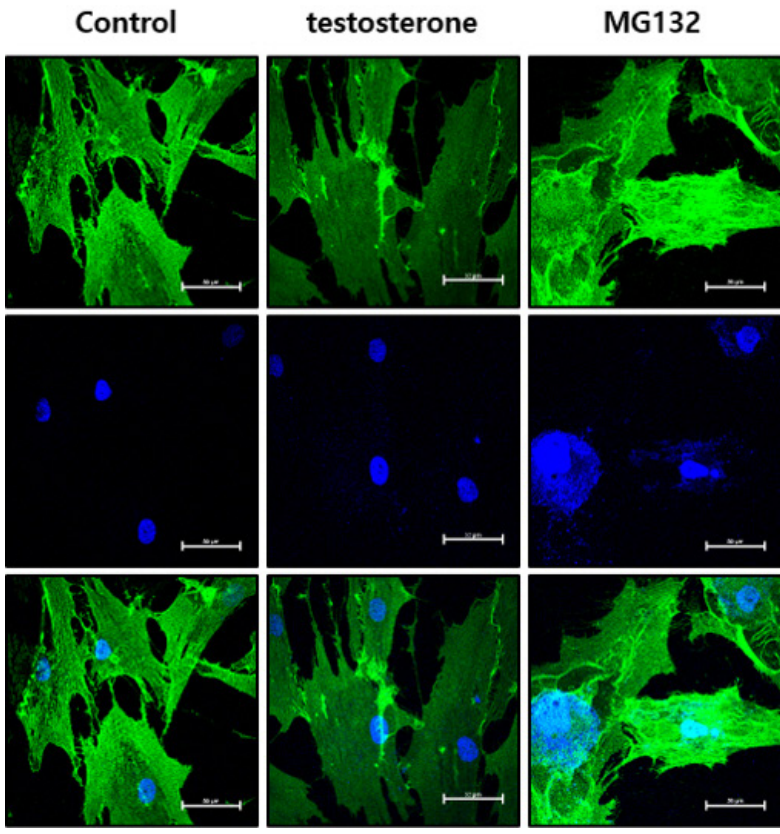

MG132+testosterone

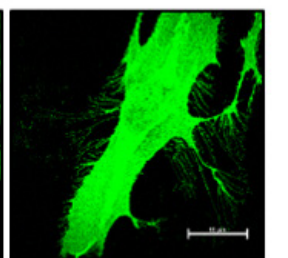

\section{$\beta$-catenin}

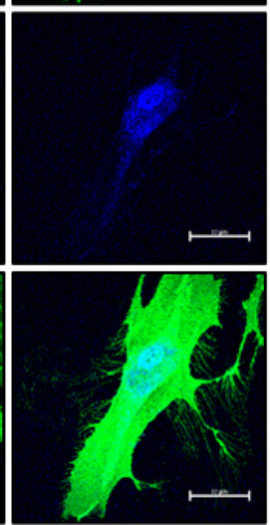

Figure 3. Ubiquitination pathway involves in the $\beta$-catenin down-regulation. Dermal papilla cells were pre-treated with MG132 for $6 \mathrm{hr}$, and then treated with testosterone. MG132 pretreatment restore the decreased $\beta$-catenin expression by testosterone. effect might be resulted from the vitamins in oil components [32]. CBD oil contains high concentration of vitamin E, which can stimulate hair growth and help improvement of alopecia [33]. Although preclinical evidence suggests topical application of CBD may be efficacious for some skin disorders, and inflammatory diseases, but elucidation of underlying molecular mechanisms have not yet to be fully identified [34]. We treated CBD to investigate molecular efficacy on dermal papilla cells. CBD treatment showed growth inhibitory effect of dermal papilla cells. Unexpectedly, CBD showed little changes on RNA level including $\beta$-catenin (Fig. 4A). No changes of $\beta$-catenin expression were also observed in immunostaining experiment. We are to examine whether CBD may have a regulatory effect in the case of combinatory treatment with testosterone or PMA. CBD was pretreated for 6 hours in dermal papilla cells and followed by treatment with testosterone or PMA. Immunostaining experiment showed that decreased $\beta$-catenin expression by testosterone or PMA was restored by CBD pretreatment (Fig. 4B, C). This phenomenon implies that $\mathrm{CBD}$ has a modulating effect on alopecia progression induced by testosterone or PMA. CBD can inhibit cell proliferation and induce apoptosis via TRPV receptor in dermal papilla cells [35]. TRPV activation secretes the proteins such as HGF, IGF1, and SCF, and promotes cell death as CBD dose-dependent manner [34]. Our current data suggest that novel efficacy of CBD is considered to have a modulating mechanism on decreased expression of $\beta$-catenin by testosterone or PMA. Numerous cell culture and animal studies showed antitumor effects of cannabinoids in various cancer types [36, 37]. CBD may enhance uptake or increase the potency of certain drugs used to treat cancer suggesting that CBD might have promising efficacy for treatment for many types of diseases including alopecia and cancers [38].

\section{CONCLUSION}

In this paper, not only we showed loss of $\beta$-catenin expression in hair tissues derived alopecia patients, but also CBD pretreatment could restore the decreased $\beta$-catenin expression by testosterone or PMA. Once focusing on $\beta$-catenin expression, $\mathrm{CBD}$ might be a modulating function for alopecia caused by hormonal or excess of signaling pathway. Therefore, CBD might have a modulating function on alopecia caused by hormonal or excess of signaling pathway, and be a promising application for on alopecia treatment.

\section{ACKNOWLEDGEMENT}

This work was supported by fund provided from Chuncheon Bioindustry Foundation (CBF), Chuncheon City, Kangwon-Do, Republic of Korea.

\section{CONFLICT OF INTEREST}

All authors declare no conflict of interest. 
A

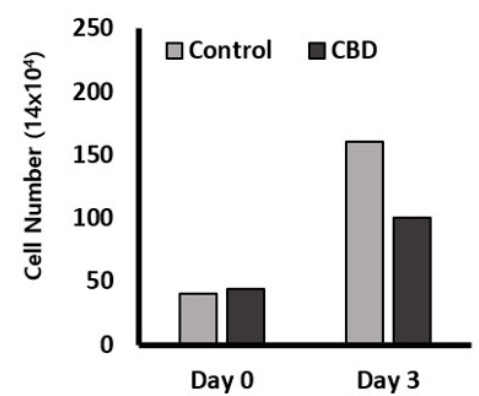

$\beta$-catenin

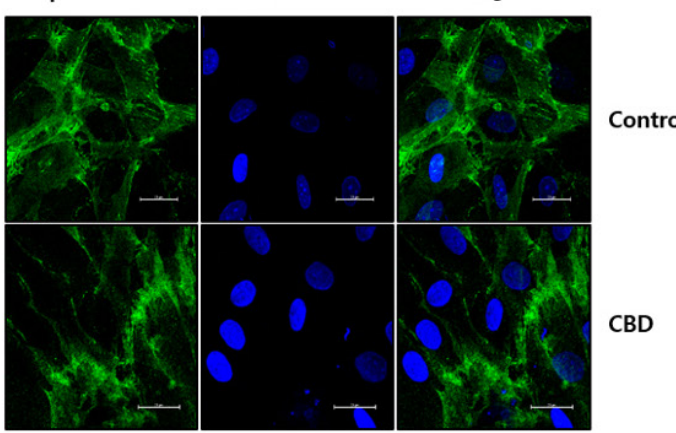

B

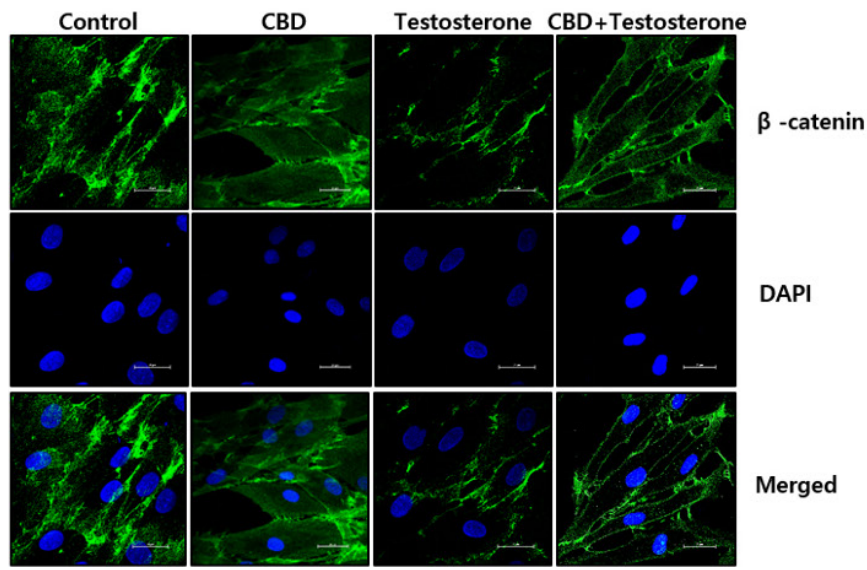

C

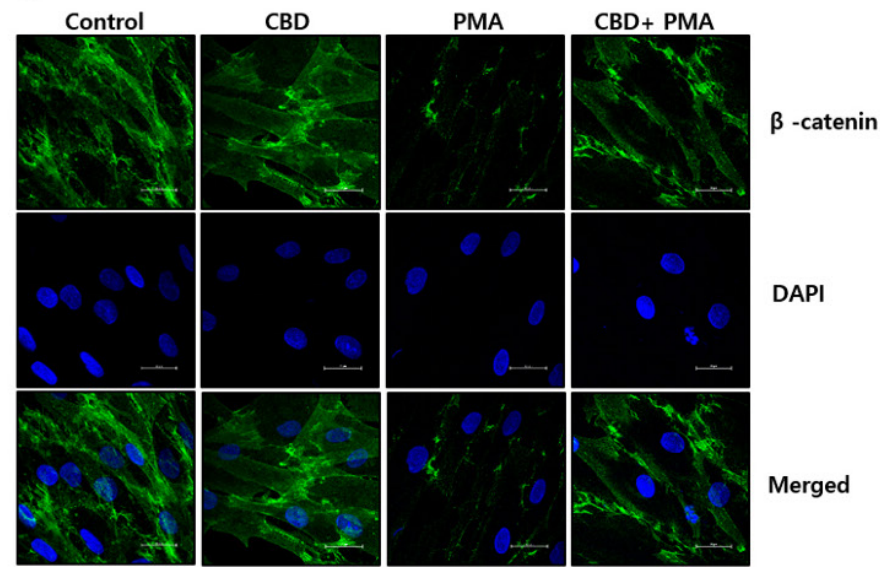

Figure 4. CBD treatment has no effect on gene expression, but restores the decreased $\beta$-catenin expression by testosterone and PMA. (A) Dermal papilla cells were treated with $20 \mu \mathrm{M}$ CBD. Cell growth was slightly inhibited at 3 day incubation. RT-PCR and immunostaining experiment shows no distinct changes on $\beta$-catenin expression. (B) CBD was pretreated for $6 \mathrm{hr}$, and then treated with testosterone in dermal papilla cells. Immunostaining experiment was performed with $\beta$-catenin antibody. (C) PMA was also treated for 3 days after CBD pretreatment in dermal papilla cells.

\section{ORCID}

Yoon-Jong Park, https://orcid.org/0000-0002-2766-6342 Jae-Min Ryu, https://orcid.org/0000-0002-2431-2362 Han-Heom Na, https://orcid.org/0000-0003-3753-3129 Hyun-Suk Jung, https://orcid.org/0000-0002-2431-1327 Bokhye Kim, https://orcid.org/0000-0001-5921-5071 Jin-Sung Park, https://orcid.org/0000-0002-1963-3938 Byung-Soo Ahn, https://orcid.org/0000-0002-0459-303X Keun-Cheol Kim, https://orcid.org/0000-0003-3047-0380

\section{REFERENCES}

1. Houschyar KS, Borrelli MR, Tapking C, Popp D, Puladi B, Ooms $\mathrm{M}$, et al. Molecular mechanisms of hair growth and regeneration: current understanding and novel paradigms. Dermatology.
2020;236(4):271-80.

2. Premanand A, Reena Rajkumari B. Androgen modulation of Wnt/ $\beta$-catenin signaling in androgenetic alopecia. Arch Dermatol Res. 2018;310(5):391-9.

3. Davis BK. Phases of the hair-growth cycle. Nature. 1962;194:694.

4. Iino M, Ehama R, Nakazawa Y, Iwabuchi T, Ogo M, Tajima M, et al. Adenosine stimulates fibroblast growth factor-7 gene expression via adenosine A2b receptor signaling in dermal papilla cells. J Invest Dermatol. 2007;127(6):1318-25.

5. Enshell-Seijffers D, Lindon C, Kashiwagi M, Morgan BA. Betacatenin activity in the dermal papilla regulates morphogenesis and regeneration of hair. Dev Cell. 2010;18(4):633-42.

6. Petiot A, Conti FJ, Grose R, Revest JM, Hodivala-Dilke KM, Dickson C. A crucial role for Fgfr2-IIIb signalling in epidermal development and hair follicle patterning. Development. 2003;130(22):5493-501.

7. Rosenquist TA, Martin GR. Fibroblast growth factor signalling 
in the hair growth cycle: expression of the fibroblast growth factor receptor and ligand genes in the murine hair follicle. Dev Dyn. 1996;205(4):379-86.

8. Schlake T. FGF signals specifically regulate the structure of hair shaft medulla via IGF-binding protein 5. Development. 2005;132(13):2981-90.

9. Clevers H, Nusse R. Wnt/ $\beta$-catenin signaling and disease. Cell. 2012;149(6):1192-205.

10. Nusse $R$, Clevers $H$. Wnt/ $\beta$-catenin signaling, disease, and emerging therapeutic modalities. Cell. 2017;169(6):985-99.

11. Breitkopf T, Leung G, Yu M, Wang E, McElwee KJ. The basic science of hair biology: what are the causal mechanisms for the disordered hair follicle? Dermatol Clin. 2013;31(1):1-19.

12. Fischer TW, Hipler UC, Elsner P. Effect of caffeine and testosterone on the proliferation of human hair follicles in vitro. Int J Dermatol. 2007;46(1):27-35.

13. Berger RA, Orentreich N, Auerbach R. Failure of topical testosterone in male-pattern alopecia. JAMA. 1968;204(6):451-2.

14. Prager N, Bickett K, French N, Marcovici G. A randomized, double-blind, placebo-controlled trial to determine the effectiveness of botanically derived inhibitors of 5-alpha-reductase in the treatment of androgenetic alopecia. J Altern Complement Med. 2002;8(2):143-52.

15. Saad F, Röhrig G, von Haehling S, Traish A. Testosterone deficiency and testosterone treatment in older men. Gerontology. 2017;63(2):144-56.

16. Nelson AM, Garza LA. Bad hair day: testosterone and Wnts. J Invest Dermatol. 2015;135(11):2567-9.

17. Olsen EA, Hordinsky M, Whiting D, Stough D, Hobbs S, Ellis $\mathrm{ML}$, et al. The importance of dual 5alpha-reductase inhibition in the treatment of male pattern hair loss: results of a randomized placebo-controlled study of dutasteride versus finasteride. J Am Acad Dermatol. 2006;55(6):1014-23.

18. Jain R, De-Eknamkul W. Potential targets in the discovery of new hair growth promoters for androgenic alopecia. Expert Opin Ther Targets. 2014;18(7):787-806.

19. Kwack MH, Ahn JS, Kim MK, Kim JC, Sung YK. Dihydrotestosterone-inducible IL-6 inhibits elongation of human hair shafts by suppressing matrix cell proliferation and promotes regression of hair follicles in mice. J Invest Dermatol. 2012;132(1):43-9.

20. Rishikaysh P, Dev K, Diaz D, Qureshi WM, Filip S, Mokry J. Signaling involved in hair follicle morphogenesis and development. Int J Mol Sci. 2014;15(1):1647-70.

21. Eicheler W, Huth A, Happle R, Hoffmann R. Phorbol-myristateacetate, but not interleukin-1 beta or insulin-like growth factorI, regulates protein kinase $\mathrm{C}$ isoenzymes in human dermal papilla cells. Acta Derm Venereol. 1997;77(5):361-4.

22. Ryan M. Cannabidiol in epilepsy: the indications and beyond.
Ment Health Clin. 2020;10(6):317-25.

23. Silvestro S, Mammana S, Cavalli E, Bramanti P, Mazzon E. Use of cannabidiol in the treatment of epilepsy: efficacy and security in clinical trials. Molecules. 2019;24(8):1459.

24. Thomas A, Baillie GL, Phillips AM, Razdan RK, Ross RA, Pertwee RG. Cannabidiol displays unexpectedly high potency as an antagonist of $\mathrm{CB} 1$ and $\mathrm{CB} 2$ receptor agonists in vitro. Br J Pharmacol. 2007;150(5):613-23.

25. Parker LA, Mechoulam R, Schlievert C. Cannabidiol, a nonpsychoactive component of cannabis and its synthetic dimethylheptyl homolog suppress nausea in an experimental model with rats. Neuroreport. 2002;13(5):567-70.

26. Chagas MH, Zuardi AW, Tumas V, Pena-Pereira MA, Sobreira ET, Bergamaschi MM, et al. Effects of cannabidiol in the treatment of patients with Parkinson's disease: an exploratory double-blind trial. J Psychopharmacol. 2014;28(11):1088-98.

27. Szabó IL, Lisztes E, Béke G, Tóth KF, Paus R, Oláh A, et al. The phytocannabinoid (-)-cannabidiol operates as a complex, differential modulator of human hair growth: anti-inflammatory submicromolar versus hair growth inhibitory micromolar effects. J Invest Dermatol. 2020;140(2):484-8.e5.

28. Thom E. Stress and the hair growth cycle: cortisol-induced hair growth disruption. J Drugs Dermatol. 2016;15(8):1001-4.

29. Kitagawa T, Matsuda K, Inui S, Takenaka H, Katoh N, Itami S, et al. Keratinocyte growth inhibition through the modification of Wnt signaling by androgen in balding dermal papilla cells. J Clin Endocrinol Metab. 2009;94(4):1288-94.

30. Lee SH, Yoon J, Shin SH, Zahoor M, Kim HJ, Park PJ, et al. Valproic acid induces hair regeneration in murine model and activates alkaline phosphatase activity in human dermal papilla cells. PLoS One. 2012;7(4):e34152.

31. Huelsken J, Vogel R, Erdmann B, Cotsarelis G, Birchmeier W. Beta-catenin controls hair follicle morphogenesis and stem cell differentiation in the skin. Cell. 2001;105(4):533-45.

32. Goluch-Koniuszy ZS. Nutrition of women with hair loss problem during the period of menopause. Prz Menopauzalny. 2016;15(1):56-61.

33. Ekanayake-Mudiyanselage S, Thiele J. [Sebaceous glands as transporters of vitamin E]. Hautarzt. 2006;57(4):291-6. German.

34. Bodó E, Bíró T, Telek A, Czifra G, Griger Z, Tóth BI, et al. A hot new twist to hair biology: involvement of vanilloid receptor-1 (VR1/TRPV1) signaling in human hair growth control. Am J Pathol. 2005;166(4):985-98.

35. Borbíró I, Lisztes E, Tóth BI, Czifra G, Oláh A, Szöllosi AG, et al. Activation of transient receptor potential vanilloid-3 inhibits human hair growth. J Invest Dermatol. 2011;131(8):1605-14.

36. Go YY, Kim SR, Kim DY, Chae SW, Song JJ. Cannabidiol enhances cytotoxicity of anti-cancer drugs in human head and 
neck squamous cell carcinoma. Sci Rep. 2020;10(1):20622.

37. Massi P, Solinas M, Cinquina V, Parolaro D. Cannabidiol as potential anticancer drug. Br J Clin Pharmacol. 2013;75(2):303-12.
38. Seltzer ES, Watters AK, MacKenzie D Jr, Granat LM, Zhang D. Cannabidiol (CBD) as a promising anti-cancer drug. Cancers (Basel). 2020;12(11):3203. 